\title{
Sensitivity of Climate Change Induced by the Weakening of the Atlantic Meridional Overturning Circulation to Cloud Feedback
}

\author{
RONG ZHANG \\ NOAA/Geophysical Fluid Dynamics Laboratory, Princeton, New Jersey \\ SARAH M. KANG \\ Program in Atmospheric and Oceanic Sciences, Princeton University, Princeton, New Jersey \\ ISAAC M. HELD \\ NOAA/Geophysical Fluid Dynamics Laboratory, Princeton, New Jersey
}

(Manuscript received 6 March 2009, in final form 28 July 2009)

\begin{abstract}
A variety of observational and modeling studies show that changes in the Atlantic meridional overturning circulation (AMOC) can induce rapid global-scale climate change. In particular, a substantially weakened AMOC leads to a southward shift of the intertropical convergence zone (ITCZ) in both the Atlantic and the Pacific Oceans. However, the simulated amplitudes of the AMOC-induced tropical climate change differ substantially among different models. In this paper, the sensitivity to cloud feedback of the climate response to a change in the AMOC is studied using a coupled ocean-atmosphere model [the GFDL Coupled Model, version 2.1 (CM2.1)]. Without cloud feedback, the simulated AMOC-induced climate change in this model is weakened substantially. Low-cloud feedback has a strong amplifying impact on the tropical ITCZ shift in this model, whereas the effects of high-cloud feedback are weaker. It is concluded that cloud feedback is an important contributor to the uncertainty in the global response to AMOC changes.
\end{abstract}

\section{Introduction}

Paleoclimate records from different tropical regions reveal abrupt changes that are coherent with the abrupt climate changes recorded in the Greenland ice cores during the glacial period. Data from the Cariaco Basin suggest that the Atlantic Ocean ITCZ shifted southward during cooling stadials of the Greenland DansgaardOeschger (D-O) oscillations (Peterson et al. 2000). Stott et al. (2002) provide evidence that Greenland cooling events were related to a southward shift of the ITCZ in the tropical Pacific Ocean. Cool conditions over Greenland were associated with weakened East Asian (Wang et al. 2001) and Indian summer monsoon (Altabet et al. 2002). Similar global-scale synchronous changes on multidecadal to centennial time scales have also been found

Corresponding author address: Rong Zhang, NOAA/GFDL, Princeton University Forrestal Campus, 201 Forrestal Rd., Princeton, NJ 08540.

E-mail: rong.zhang@noaa.gov during the Holocene. There are suggestions that the Atlantic ITCZ shifted southward during the Little Ice Age and northward during the Medieval Warm Period (Haug et al. 2001). Sediment records in the Arabian Sea show a weaker summer monsoon during the Little Ice Age and an enhanced summer monsoon during the Medieval Warm Period (Gupta et al. 2003).

This global synchronization of climate changes, especially the southward shift of the ITCZ in both Atlantic and Pacific, is thought to be induced by the weakening of the Atlantic meridional overturning circulation (AMOC). Paleoproxies from the Bermuda Rise (McManus et al. 2004) further indicate that the AMOC was substantially weakened during the Younger Dryas cooling event and was almost shut down during the latest (H1) Heinrich event. The AMOC transports a substantial amount of heat northward. Shutdown of the AMOC causes a cooling in the North Atlantic and a warming in the South Atlantic, associated with the reduction of the northward ocean heat transport, as simulated by many climate models (Manabe and Stouffer 1995; Vellinga and Wood 2002; 
Dahl et al. 2005; Zhang and Delworth 2005; Stouffer et al. 2006). In models, weakening of the AMOC also induces significant remote responses outside the Atlantic, such as a southward shift of the ITCZ in the tropical Pacific and the weakening of the Indian and East Asian summer monsoons (Zhang and Delworth 2005) as well as strengthening of the Aleutian low and large-scale cooling in the central North Pacific (Mikolajewicz et al. 1997; Zhang and Delworth 2005).

In summary, changes in the AMOC can have a profound impact on the climate system. An accurate estimation of the impact of the AMOC is crucial for assessing and predicting future climate changes and the potential for rapid climate change. However, the currently simulated amplitudes of the AMOC-induced global-scale climate change are very different in different climate models (Stouffer et al. 2006). The uncertainty in cloud feedback is often cited as the leading reason that climate models have widely varying temperature responses to increased greenhouse gas concentrations (Cess et al. 1989; Weilicki et al. 1996). The importance of cloud feedback for the climate response to AMOC variations is less well appreciated. A recent study using an idealized version of the Geophysical Fluid Dynamics Laboratory's atmospheric general circulation model (GFDL AM2; Anderson et al. 2004) over a slab ocean (Kang et al. 2008) shows that the tropical response to extratropical thermal forcing is very sensitive to cloud feedback, suggesting that uncertainty in cloud feedback is also a key source of uncertainty in simulations of abrupt climate change. Motivated by the Kang et al. (2008) study, we examine here the importance of cloud feedback in a climate model's response to an AMOC perturbation, using GFDL's Coupled Model, version 2.1 (CM2.1). We disable cloud feedback by overriding the cloud amounts and properties in the radiation calculation of CM2.1 with values that have the same climatological mean as in the CM2.1 control simulation. The AMOC is perturbed with an injection of freshwater in the North Atlantic and the response is compared with predicted and with prescribed clouds.

In section 2, the model and experimental design are described. The sensitivity of the climate change to cloud feedback is described in section 3. The physical mechanisms involved are discussed in section 4 . The discussion and conclusion are given in section 5 .

\section{Description of model and experimental design}

The model we employed here is a fully coupled oceanatmosphere global general circulation model developed at the GFDL for the Intergovernmental Panel on Climate Change Fourth Assessment Report (the GFDL
CM2.1; Delworth et al. 2006). The ocean model employs an explicit free surface and a true freshwater flux exchange between the ocean and atmosphere. It has 50 vertical levels ( 22 levels of $10-\mathrm{m}$ thickness each in the top $220 \mathrm{~m}$ ) and $1^{\circ}$ zonal resolution. The meridional resolution is $1^{\circ}$ outside the tropics and is refined to $1 / 3^{\circ}$ at the equator. The atmosphere model has 24 vertical levels with horizontal resolution of $2^{\circ}$ latitude $\times 2.5^{\circ}$ longitude. The control simulation uses 1860 radiative forcing conditions and produces a stable preindustrial climate without flux adjustments (Delworth et al. 2006). To explore the response of the global climate to a weakening of the AMOC, a water-hosing experiment is conducted in which an idealized strong extra freshwater forcing of $0.6 \mathrm{~Sv}$ $\left(1 \mathrm{~Sv} \equiv 10^{6} \mathrm{~m}^{3} \mathrm{~s}^{-1}\right)$ is uniformly distributed over the northern North Atlantic $\left(55^{\circ}-75^{\circ} \mathrm{N}, 63^{\circ} \mathrm{W}-4^{\circ} \mathrm{E}\right)$ for the entire 60-yr duration of the experiment. The anomaly is defined as the 40-yr (years 21-60) averaged difference between perturbed and control experiments. All quantities shown in this paper are annual mean values.

To understand the role of cloud feedback in the AMOC-induced climate change, we disable the cloud feedback by prescribing in the radiation calculation the three prognostic cloud properties (total cloud liquid in each grid box, total cloud ice in each grid box, and the fraction of each grid box covered by cloud) at all points and all 24 vertical levels. The three cloud properties used in the radiation calculation were prescribed every time step $(3 \mathrm{~h})$ to maintain high-frequency variations and were taken from one year of the control simulation chosen arbitrarily. These clouds fields are repeated for every year of the simulation. The prescribed 3-hourly cloud properties are adjusted to have the same climatological monthly mean as that in CM2.1 control simulation so that the simulated climatology is similar to that in the CM2.1 control simulation (details are described in the appendix). This modified CM2.1 with no cloud feedback is referred to as $N_{\mathrm{CF}}$ hereinafter. The control and water-hosing experiments were each conducted with $N_{\mathrm{CF}}$ for $60 \mathrm{yr}$. The water-hosing experiment has the same extra freshwater forcing as that used for CM2.1. Again the anomaly is defined as the 40-yr (years 21-60) averaged difference between perturbed and control experiments. The 60 -yr control simulation using $N_{\mathrm{CF}}$ produces a "climatology" that is similar to the CM2.1 control run (appendix) and shows a slightly stronger time-mean maximum AMOC (25 Sv) than that in the CM2.1 control run (23 Sv) (Fig. 1) and a slightly stronger time-mean oceanic meridional heat transport than that in CM2.1 control run. The AMOC structure in the $N_{\mathrm{CF}}$ control run is very similar to that in the CM2.1 control run. The maximum AMOC is located at $43^{\circ} \mathrm{N}$ in both control runs. 


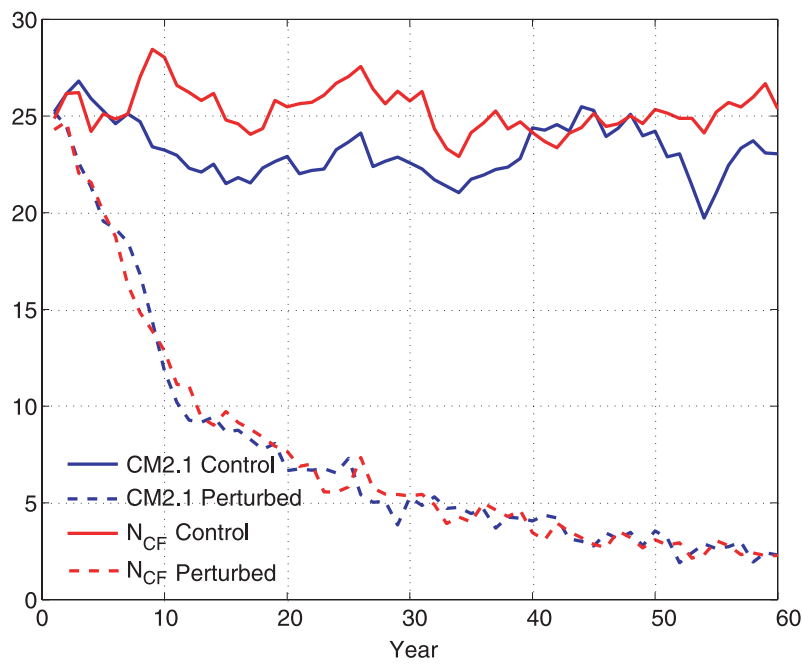

FIG. 1. Time series of the maximum AMOC strength (Sv) from $\mathrm{CM} 2.1$ and $N_{\mathrm{CF}}$. The maximum AMOC is defined as the maximum value of the annual Eulerian mean overturning streamfunction over the domain $30^{\circ}-80^{\circ} \mathrm{N}$ in the North Atlantic. Solid lines indicate control experiments, and the dashed lines are for perturbed water-hosing experiments.

\section{Sensitivity of climate change induced by the weakening of the AMOC to cloud feedback}

In both the perturbed water-hosing experiments using CM2.1 and $N_{\mathrm{CF}}$, the maximum AMOC rapidly weakens to about $7 \mathrm{~Sv}$ after $20 \mathrm{yr}$, after which the rate of decrease gradually slows, resulting in an average of $4 \mathrm{~Sv}$ from years 21 to 60 (Fig. 1 ). The $N_{\text {CF }}$ shows a slightly stronger weakening of the AMOC because of the slightly stronger climatological mean strength of the AMOC in $N_{\mathrm{CF}}$ (Fig. 1). There is a substantial cooling in the Northern Hemisphere surface temperature in CM2.1, especially over the subpolar North Atlantic region and over the region from Iceland to the Barents Sea, in response to the AMOC weakening (Fig. 2). This cooling in annual mean surface temperature over the high latitudes mainly reflects the winter signal. In CM2.1 and $N_{\mathrm{CF}}$ control simulations, there is strong deep convection in the highlatitude North Atlantic in the winter, and the warm water carried by the active AMOC releases large amount of heat into the high-latitude atmosphere. In CM2.1 and $N_{\mathrm{CF}}$ hosing experiments, the surface freshening weakens the deep convection in the high-latitude North Atlantic and thus weakens the AMOC; much less heat is released into the atmosphere, leading to the cooling of the highlatitude atmosphere. Whereas the cloud cover can adjust to the weakening of the AMOC in the CM2.1 hosing experiment, in the $N_{\mathrm{CF}}$ hosing experiment the cloud cover is kept compatible with an active AMOC as in the control experiment. In CM2.1 cloud cover in the high-
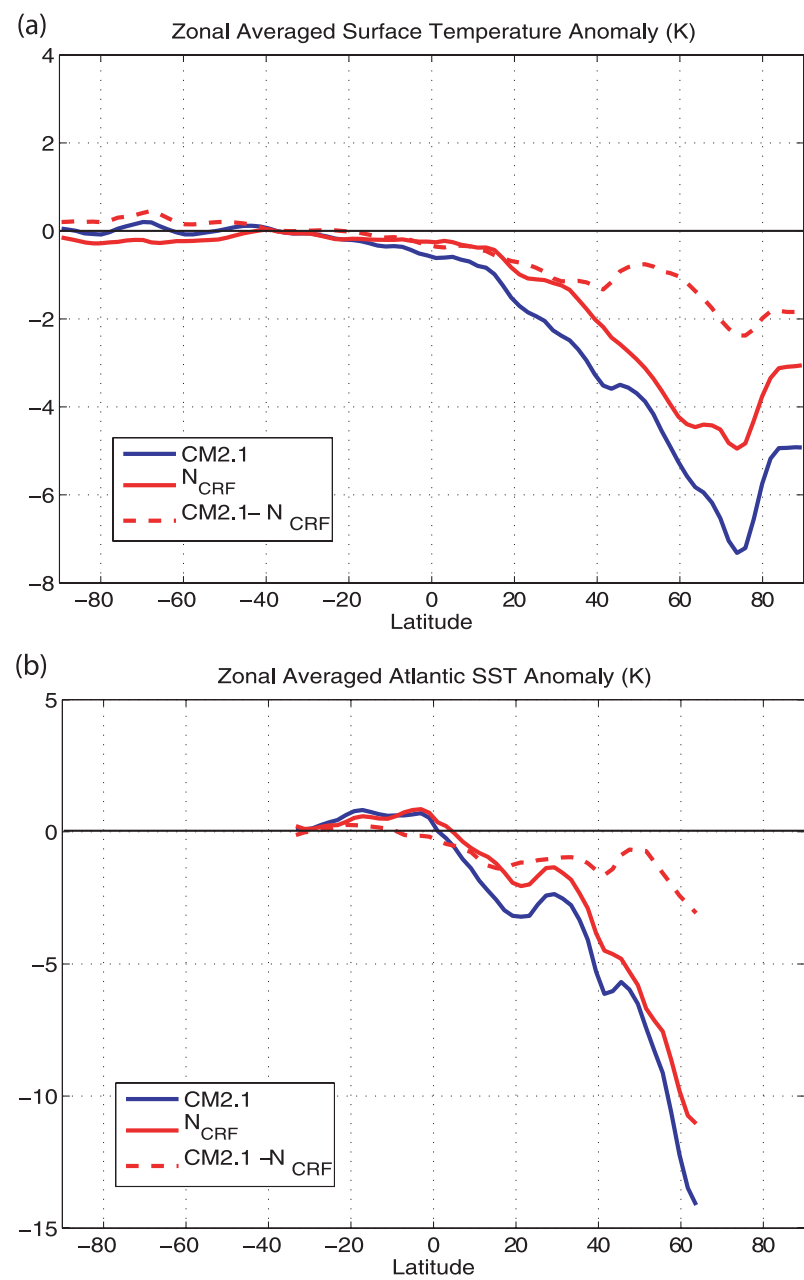

FIG. 2. Zonally averaged anomalies. (a) Zonally averaged annual mean surface temperature anomaly (K). (b) Zonally averaged annual mean surface temperature anomaly (K) over the Atlantic basin. Solid lines show the anomalous response, i.e., the difference between perturbed water-hosing and control experiments from CM2.1 (blue) and $N_{\mathrm{CF}}$ (red). The red dashed line is difference in the anomalous response between $\mathrm{CM} 2.1$ and $N_{\mathrm{CF}}$, i.e., [pertur$\operatorname{bed}(\mathrm{CM} 2.1)-\operatorname{control}(\mathrm{CM} 2.1)]-\left[\operatorname{perturbed}\left(N_{\mathrm{CF}}\right)-\operatorname{control}\left(N_{\mathrm{CF}}\right)\right]$

latitude North Atlantic increases in response to local surface cooling and the associated increase in low-level static stability, and the absence of this feedback in $N_{\mathrm{CF}}$ prevents temperatures from dropping as much as in CM2.1. In $N_{\mathrm{CF}}$, this cooling is reduced by roughly $25 \%$ in the zonal mean and by a smaller percentage over the Atlantic itself (Fig. 2), in spite of larger weakening of the AMOC. In response to the weakening of the AMOC, the global mean surface temperature is cooled by $1.8 \mathrm{~K}$ in $\mathrm{CM} 2.1$, but this cooling is reduced by about $30 \%$ to $1.3 \mathrm{~K}$ in $N_{\mathrm{CF}}$. The AMOC response itself is not modified significantly by cloud feedback, while the resulting SST changes are impacted. 


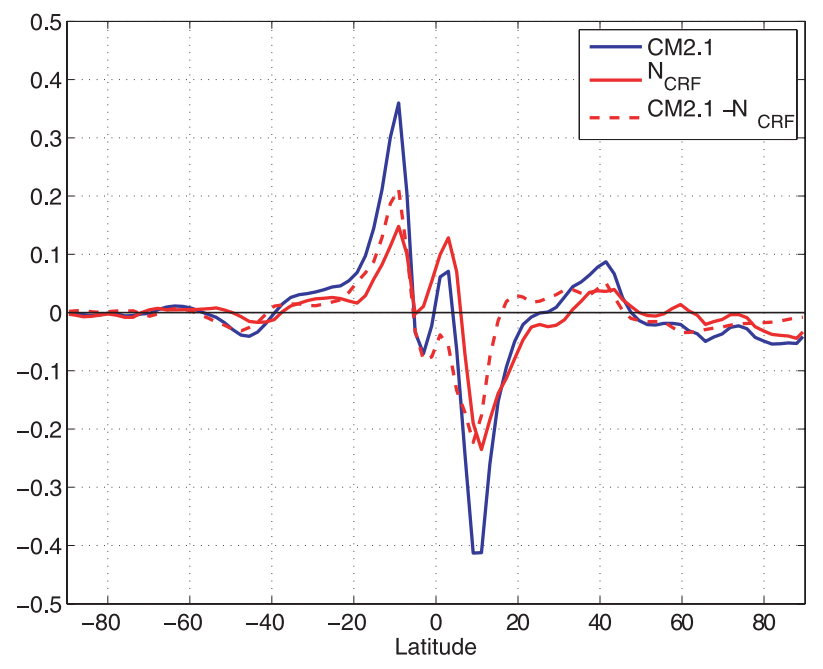

FIG. 3. As in Fig. 2a, but for $P-E$ anomaly $\left(\mathrm{m} \mathrm{yr}^{-1}\right)$.

The importance of cloud feedbacks is more evident in the tropical precipitation response. In CM2.1, the zonally averaged precipitation minus evaporation $(P-E)$ is enhanced by $0.36 \mathrm{~m} \mathrm{yr}^{-1}$ around $9^{\circ} \mathrm{S}$, and reduced by $0.41 \mathrm{~m} \mathrm{yr}^{-1}$ around $11^{\circ} \mathrm{N}$ (Fig. 3 ) in response to the substantial weakening of the AMOC, indicating southward moisture transport across the equator and a southward shift of the ITCZ. In $N_{\mathrm{CF}}$, the zonally averaged $P-E$ changes are smaller by roughly a factor of 2 . The southward ITCZ shift is associated with an anomalous crossequatorial Hadley cell, with a descending branch near $11^{\circ} \mathrm{N}$ and an ascending branch near $9^{\circ} \mathrm{S}$ in both $\mathrm{CM} 2.1$ and $N_{\mathrm{CF}}$ (Fig. 4). The strength of this Hadley cell has a maximum of $48 \times 10^{9} \mathrm{~kg} \mathrm{~s}^{-1}$ in CM2.1 (Fig. 4a) and $30 \times 10^{9} \mathrm{~kg} \mathrm{~s}^{-1}$ in $N_{\mathrm{CF}}$ (Fig. 4b).

Hence, without cloud feedback, the tropical response to the weakening AMOC, including the southward ITCZ shift and the strength of the anomalous Hadley cell, is much smaller. The same result is evident in the changes in the atmospheric energy transport (Fig. 5). In particular, the response of the atmospheric energy transport at the equator to the weakening of the AMOC is reduced by roughly a factor of 2 when clouds are prescribed. As described in Kang et al. (2008), it is useful to think of this atmospheric energy transport as a fundamental aspect of the response, in terms of which one can understand the magnitude of the changes in tropical circulation and hydrological cycle. The implication of this perspective is that the effects of cloud feedbacks on these tropical responses can be understood by considering the effects of these feedbacks on the terms in the atmospheric energy budget that balance this anomalous energy transport.

The coupled response described here has a complication not present in Kang et al. (2008), where the oceanic
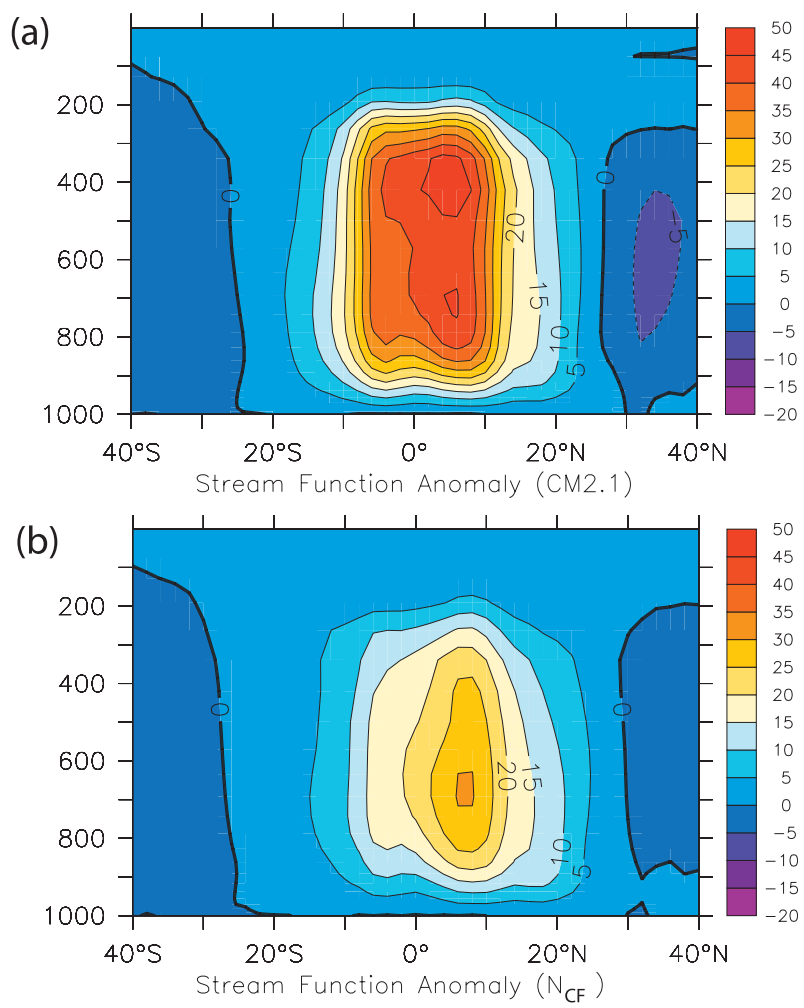

FIG. 4. Annual mean Hadley circulation anomaly $\left(10^{9} \mathrm{~kg} \mathrm{~s}^{-1}\right)$ :

(a) CM2.1 and (b) $N_{\mathrm{CF}}$.

heat transport anomaly was prescribed. Here, the oceanic heat transport response can be affected by removing the cloud feedback. The weakening of the AMOC reduces the northward oceanic heat transport. As seen in Fig. 5, the oceanic heat transport reduction in the tropics is somewhat stronger in $N_{\mathrm{CF}}$ as compared with CM2.1. This is because in CM2.1 the strong southward ITCZ shift enhances the trade winds north of the equator and reduces the trade winds south of the equator, leading to the enhancement of the northward wind-driven oceanic heat transport in the tropics, countering the thermohalinedriven reduction of ocean heat transport. In $N_{\mathrm{CF}}$ the weaker ITCZ shift leads to a smaller northward winddriven heat transport enhancement in the tropics, so the net oceanic heat transport reduction (thermohaline plus wind) is stronger.

In CM2.1, the weakening of the AMOC induces largescale cooling (warming) over the Northern (Southern) Hemisphere (Fig. 6a) and a southward shift of the ITCZ over the tropical Pacific as well as the Atlantic (Fig. 7a), consistent with previous simulations (Zhang and Delworth 2005; Stouffer et al. 2006) and the interpretation of paleoproxies. As described by Zhang and Delworth (2005), the coupling of the Pacific to the Atlantic takes place primarily through an atmospheric bridge. In $N_{\mathrm{CF}}$, 


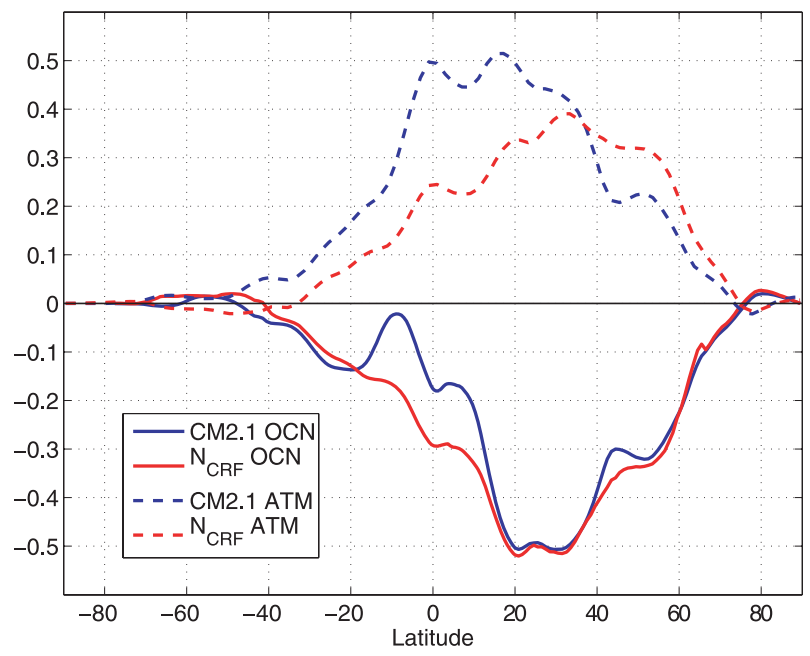

FIG. 5. Zonally integrated annual mean atmosphere (ATM) and ocean $(\mathrm{OCN})$ heat transport anomaly $(\mathrm{PW})$ from CM2.1 and $N_{\mathrm{CF}}$.

the AMOC-induced cooling over the Northern Hemisphere (especially over the subpolar North Atlantic region and over the region from Iceland to the Barents Sea), as well as warming over the Southern Hemisphere, is much weaker (Fig. 6) relative to that in CM2.1 because of the absence of cloud feedback. The southward ITCZ shift in $N_{\mathrm{CF}}$ is weakened in both the Atlantic and the Pacific (Fig. 7) relative to that in CM2.1.

\section{Cloud feedback}

To understand how the AMOC-induced rapid climate change is affected by cloud feedback, we examine the anomalous low-cloud ( $p>680 \mathrm{hPa}$ ) and high-cloud $(p<440 \mathrm{hPa})$ fractions and the anomalous shortwave (SW) and longwave (LW) cloud radiative forcing (CRF) at the top of the atmosphere (TOA). The SW/LW CRF is defined as the difference between the downward totalsky SW/LW radiative flux at TOA and the downward clear-sky SW/LW radiative flux at TOA.

In CM2.1, the AMOC-induced surface cooling over the North Atlantic stabilizes the atmosphere, weakens the deep convection and the associated compensating subsidence, and enhances shallow convection, leading to an increase in low cloud cover (Fig. 8a). Similarly, the AMOC-induced surface warming over the South Atlantic destabilizes the atmosphere and thus strengthens deep convection, resulting in a decrease in low cloud cover (Fig. 8a). Because SST dominates the temperature of the surface boundary layer, low cloud that forms in the boundary layer is very sensitive to SST. Klein and Hartmann (1993) shows that observed low-cloud amount increases with the static stability of the lower troposphere at the seasonal time scale. Norris and Leovy (1994) studied observed long-term global datasets of cloudiness and SST and found significant negative correlation between the low cloud amount and SST over midlatitude oceans at the interannual time scale as well as in the long-term trend. In addition to these low-cloud changes, there is a southward shift of the high cloud cover in CM2.1 over both the tropical Atlantic and the tropical Pacific in association with the southward shift of the ITCZ (Fig. 8b).

In CM2.1, there is also a substantial reduction of the SW CRF over the mid-low latitudes of the North Atlantic (Fig. 9a), which has the same spatial pattern as the enhancement of the low cloud cover, providing a positive feedback to the cooling of the atmosphere-ocean system in that region generated by the anomalous oceanic circulation. Similarly, there is a smaller increase of the SW CRF over the South Atlantic, providing a positive feedback to the warming of the atmosphere-ocean system there. The net anomalous CRF ( SW + LW) induced by the anomalous high cloud cover over the tropics is small because of the cancellation between SW and LW effects (Fig. 9). The net CRF anomaly provides a positive feedback to the AMOC-induced response over most of the globe (Figs. 6a, 9a).

There is potential ambiguity in the physical interpretation of changes in cloud radiative forcing in experiments such as these, as discussed most recently by Soden et al. (2004). But this ambiguity primarily affects the longwave cloud forcing. Since the dominant change here is in the shortwave, we can be confident that the low-cloud shortwave forcing is the primary factor in amplifying the magnitude of the response to the AMOC reduction.

To check on this conclusion, we conduct two additional sets of experiments. First, we disable the highcloud feedback by prescribing the three prognostic cloud properties (cloud liquid, cloud ice, and cloud fraction) at all grid points above the 440-hPa level in the radiation calculation of $\mathrm{CM} 2.1$ using the same method as in $N_{\mathrm{CF}}$ (appendix). This modified CM2.1 is referred to as $N_{\text {HCF }}$ hereinafter. Secondly, we disable the low-cloud feedback by prescribing cloud properties at all grid points below the $680-\mathrm{hPa}$ level in an identical fashion. This modified CM2.1 is referred to as $N_{\mathrm{LCF}}$ hereinafter. The control and perturbed water-hosing experiments were conducted for $60 \mathrm{yr}$, respectively, using both $N_{\mathrm{HCF}}$ and $N_{\mathrm{LCF}}$, in identical fashion to the experiments with $N_{\mathrm{CF}}$. The control run of $N_{\mathrm{LCF}}$ has a much larger time mean maximum AMOC strength (34 Sv), and the control run of $N_{\mathrm{HCF}}$ has a slightly weaker time mean maximum AMOC strength $(20 \mathrm{~Sv})$, relative to that in CM2.1. The maximum AMOC is reduced to an average of $4 \mathrm{~Sv}$ from years 21 to 60 in the perturbed water-hosing experiments using $N_{\mathrm{HCF}}$ and reduced to $5 \mathrm{~Sv}$ in the perturbed 
(a)

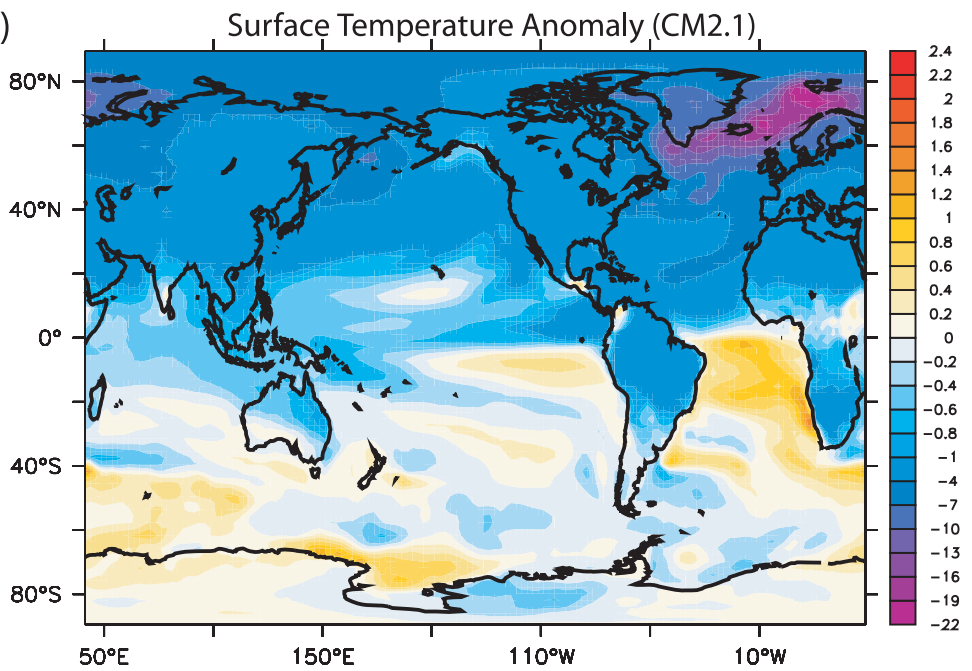

(b)

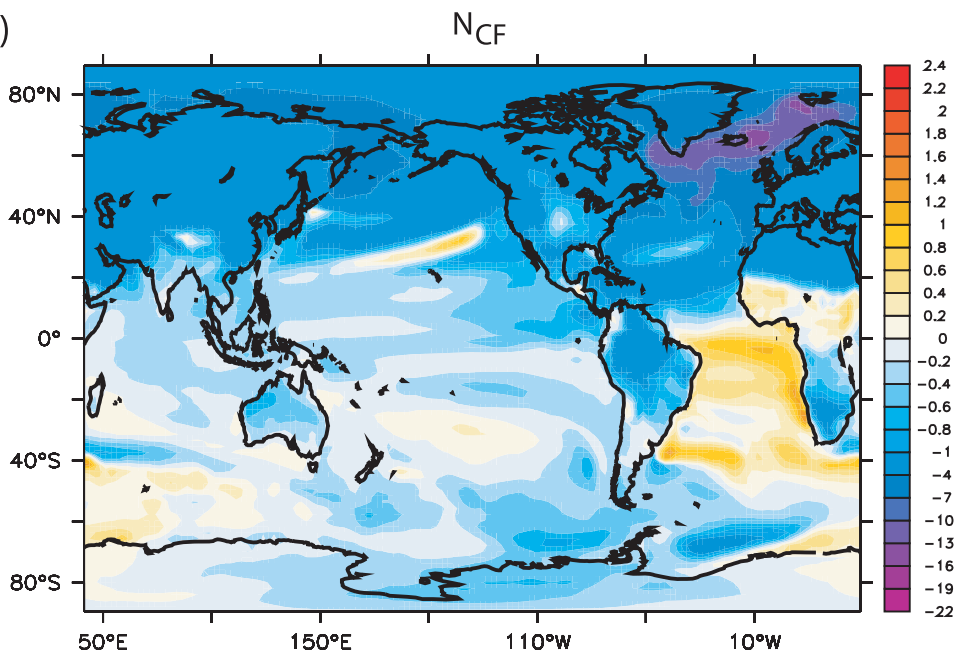

(c)

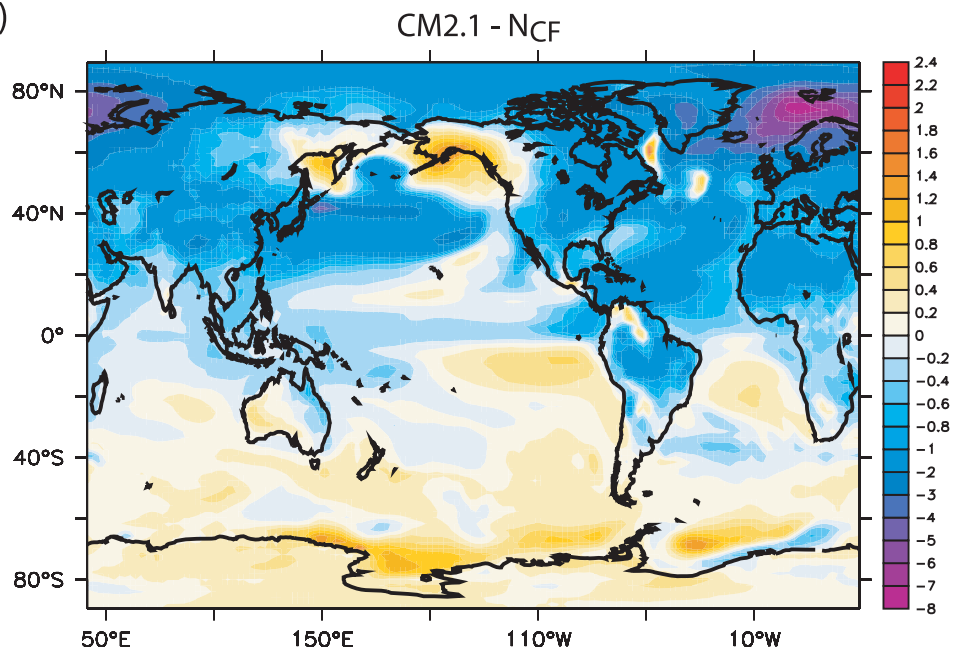

FIG. 6. Annual mean surface temperature anomaly (K). Anomalous response, i.e., difference between perturbed water-hosing and control experiments from (a) CM2.1 and (b) $N_{\mathrm{CF}}$. (c) Difference in the anomalous response between CM2.1 and $N_{\mathrm{CF}}$, i.e., $[$ perturbed(CM2.1) $-\operatorname{control}(\mathrm{CM} 2.1)]-\left[\operatorname{perturbed}\left(N_{\mathrm{CF}}\right)-\operatorname{control}\left(N_{\mathrm{CF}}\right)\right]$. 

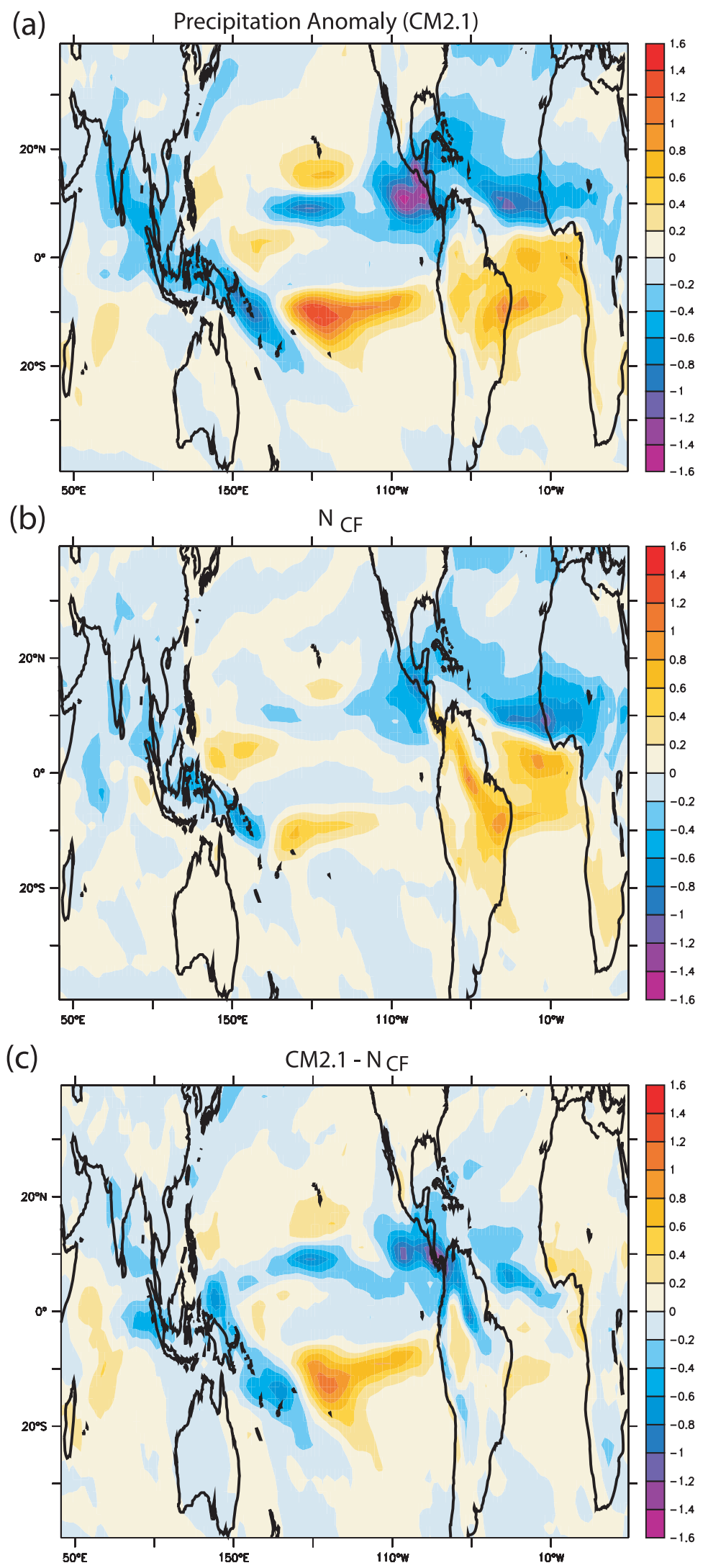

FIG. 7. As in Fig. 6, but for precipitation anomaly $\left(\mathrm{m} \mathrm{yr}^{-1}\right)$. 

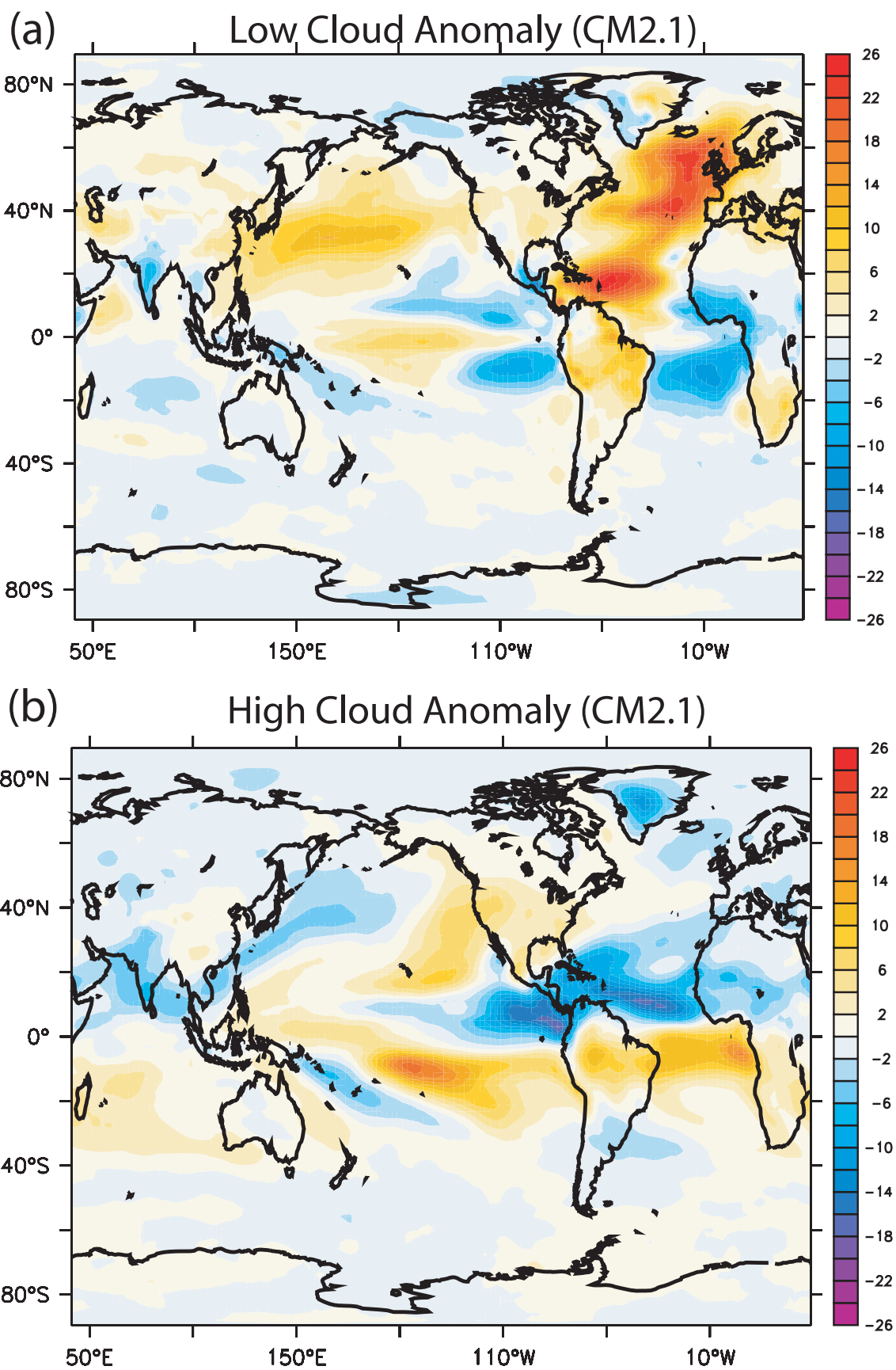

FIG. 8. Annual mean (a) low-cloud-amount and (b) high-cloud-amount anomaly (\%) from CM2.1.

water-hosing experiments using $N_{\mathrm{LCF}}$. Hence, $N_{\mathrm{LCF}}$ shows a much stronger weakening of the AMOC because of the stronger climatological mean strength of the AMOC in $N_{\text {LCF. }}$.

Figure 10a compares the global zonally averaged $P-E$ anomaly in response to the weakening of the AMOC in $N_{\mathrm{HCF}}$ and $N_{\mathrm{LCF}}$ with that in CM2.1 and $N_{\mathrm{CF}}$. In $N_{\mathrm{HCF}}$, the enhancement of $P-E$ around $9^{\circ} \mathrm{S}$ is similar to that in CM2.1 while the reduction of $P-E$ around $11^{\circ} \mathrm{N}$ is smaller than that in CM2.1 but larger than that in $N_{\mathrm{CF}}$ (Fig. 10a). In $N_{\mathrm{LCF}}$, the enhancement of $P-E$ around $9^{\circ} \mathrm{S}$ and the reduction of $P-E$ around $11^{\circ} \mathrm{N}$ are both smaller than that in $N_{\mathrm{CF}}$ (Fig. 10a), despite a much stronger weakening of the AMOC in $N_{\mathrm{LCF}}$. This result suggests that the AMOC-induced southward shift of the ITCZ is more sensitive to low-cloud feedback than to 
(a) SW CRF Anomaly (CM2.1)

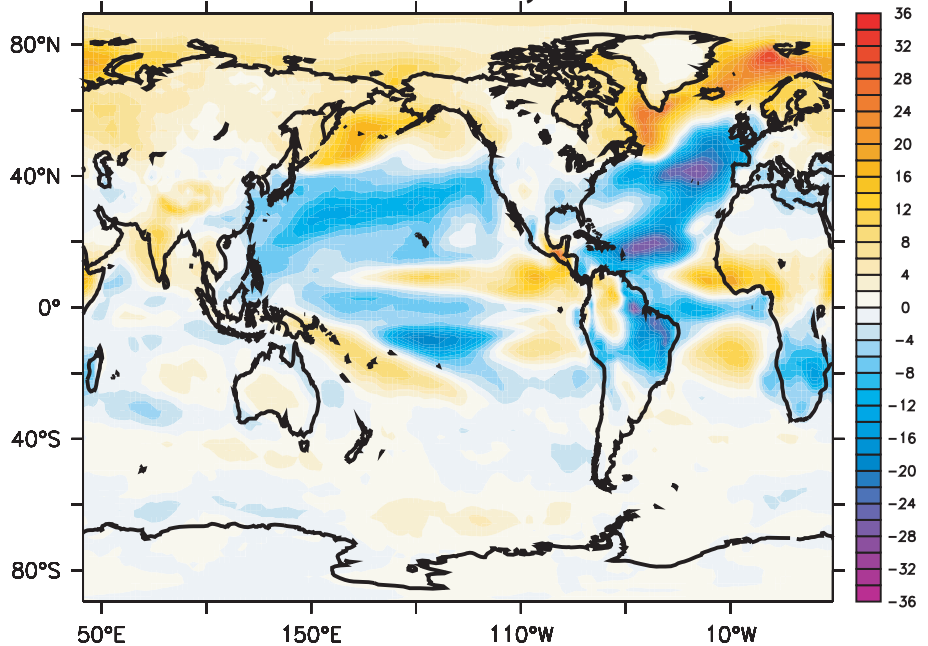

(b)

LW CRF Anomaly (CM2.1)

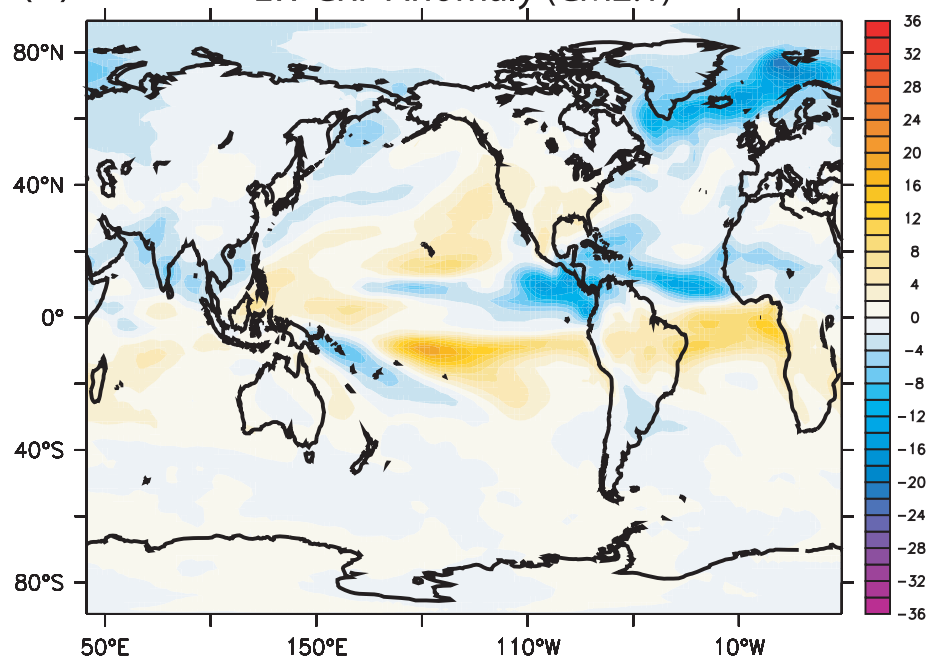

(c)

NET CRF Anomaly (CM2.1)

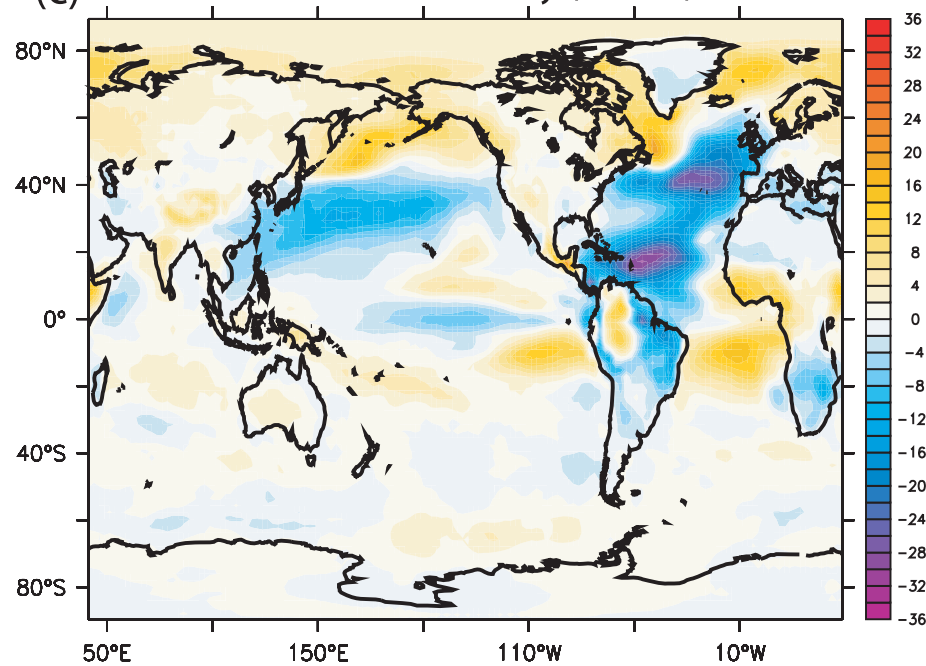

FIG. 9. Annual mean SW, LW, and total $(\mathrm{SW}+\mathrm{LW}=\mathrm{NET}) \mathrm{CRF}$ anomaly $\left(\mathrm{W} \mathrm{m}^{-2}\right)$ from CM2.1. Positive values denote downward flux at the TOA. 
(a)

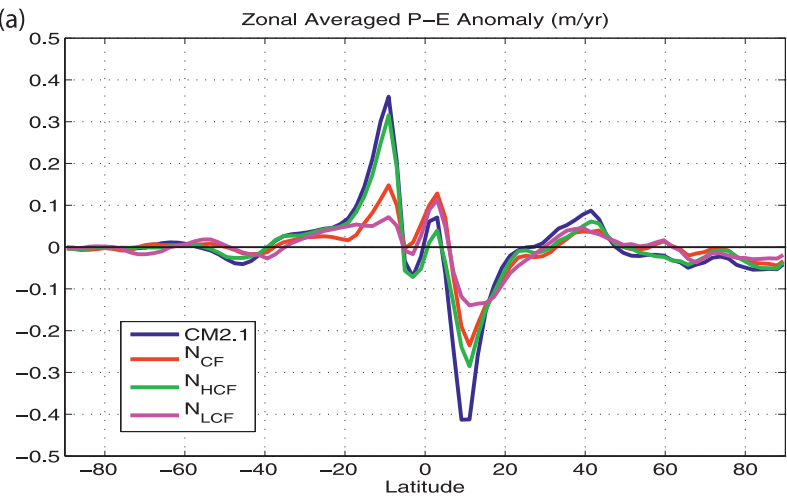

(b)

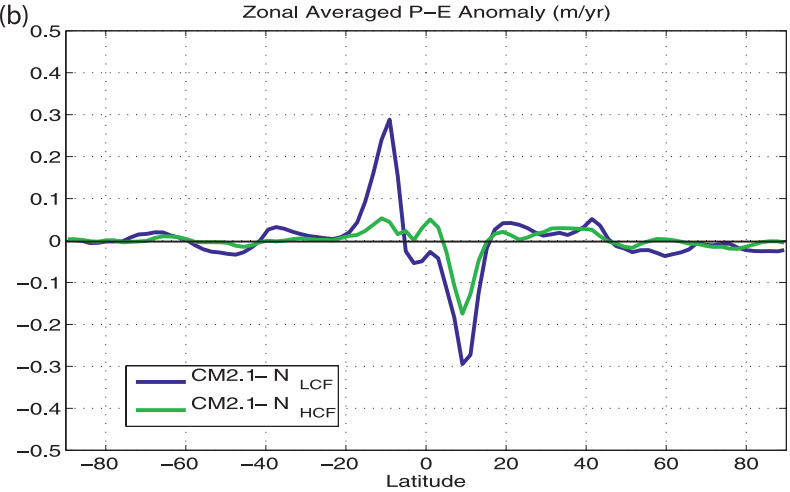

FIG. 10. Zonally averaged annual mean $P-E$ anomaly $\left(\mathrm{m} \mathrm{yr}^{-1}\right)$. (a) Anomaly from CM2.1, $N_{\mathrm{CF}}, N_{\mathrm{HCF}}$, and $N_{\mathrm{LCF}}$. (b) Difference in the anomaly between CM2.1 and $N_{\mathrm{HCF}}$, i.e., [perturbed(CM2.1) control(CM2.1)] - [perturbed $\left.\left(N_{\mathrm{HCF}}\right)-\operatorname{control}\left(N_{\mathrm{HCF}}\right)\right]$ and difference in the anomaly between CM2.1 and $N_{\mathrm{LCF}}$, i.e., [perturbed(CM2.1) - control(CM2.1)] - $\left[\operatorname{perturbed}\left(N_{\mathrm{LCF}}\right)-\right.$ $\left.\operatorname{control}\left(N_{\mathrm{LCF}}\right)\right]$

high-cloud feedback. The effect of low-cloud feedback can be estimated in Fig. 10b from the difference CM2.1 $N_{\mathrm{HCF}}$. Similarly, the differences CM2.1 $-N_{\mathrm{HCF}}$ give estimates of the effect of high-cloud feedback (Fig. 10b). The SW and LW CRF anomalies induced by the highcloud-cover anomaly over the tropics counter each other, with the LW CRF anomaly slightly stronger than the SW $\mathrm{CRF}$ anomaly. Hence, the net CRF anomaly induced by high cloud cover provides a weaker positive feedback.

\section{Conclusions}

In summary, in this study we show that the amplitude of global-scale abrupt climate changes induced by the weakening of the AMOC is strongly enhanced by changes in clouds in GFDL'S CM2.1 model. To the extent that cloud changes are not robust across models, one can infer that these global-scale changes will be model dependent. The simulated GFDL CM2.1 atmospheric model's cloud properties, sorted into different tropical regimes, are compared with those in two other

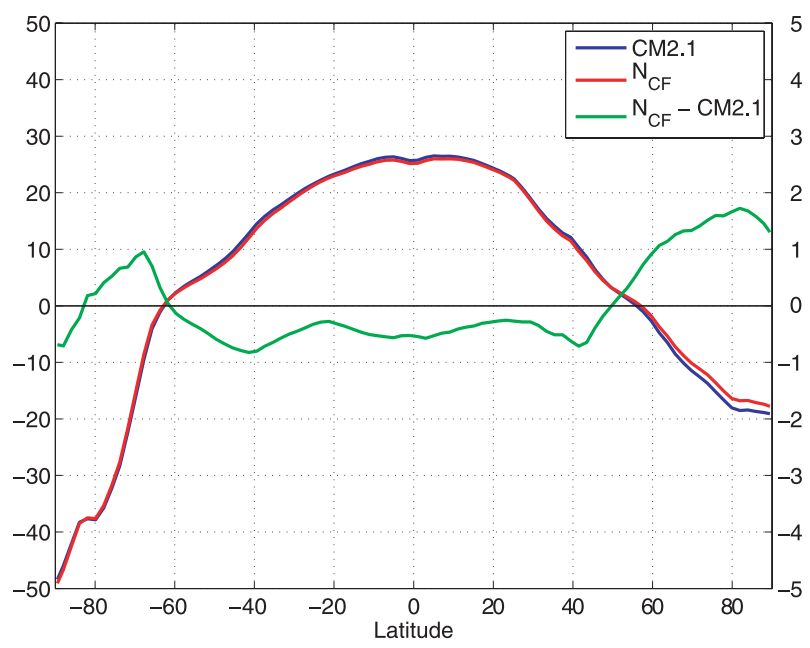

FIG. A1. Zonally averaged climatological annual mean surface temperature (K) from CM2.1 and $N_{\mathrm{CF}}$ and the difference between $N_{\mathrm{CF}}$ and CM2.1 climatological means (scale on the right axis).

atmospheric models [National Center for Atmospheric Research Community Atmosphere Model, version 3.0 (CAM 3.0) and the National Aeronautics and Space Administration Global Modeling and Assimilation Office (GMAO) Seasonal-to-Interannual Prediction Project 2 (NSIPP-2)] and the observations in a recent study (Wyant et al. 2006). This study shows that the simulated longwave and shortwave cloud forcing and in all three models agree well with Earth Radiation Budget Experiment observations. On the other hand, the three models disagree with each other and with International Satellite Cloud Climatology Project satellite observations in regime-sorted cloud fraction, condensate amount, and cloud-top height. These differences in cloud feedbacks simulated by various models because of different cloud parameterizations will likely yield different climate responses to a weakening of the AMOC.

It would be of interest to disable cloud feedbacks in this way in other climate response experiments, including the response to greenhouse-gas increases, to better isolate the effects of cloud feedback in various climate models.

Acknowledgments. We would like to thank two anonymous reviewers for very helpful comments on the earlier version of this paper. Sarah M. Kang was supported by NSF Grant ATM-0612551.

\section{APPENDIX}

\section{Description of Method}

The three cloud properties (cloud fraction, cloud liquid, cloud ice) used in the radiation calculation were prescribed every time step $(3 \mathrm{~h})$ to maintain high-frequency 


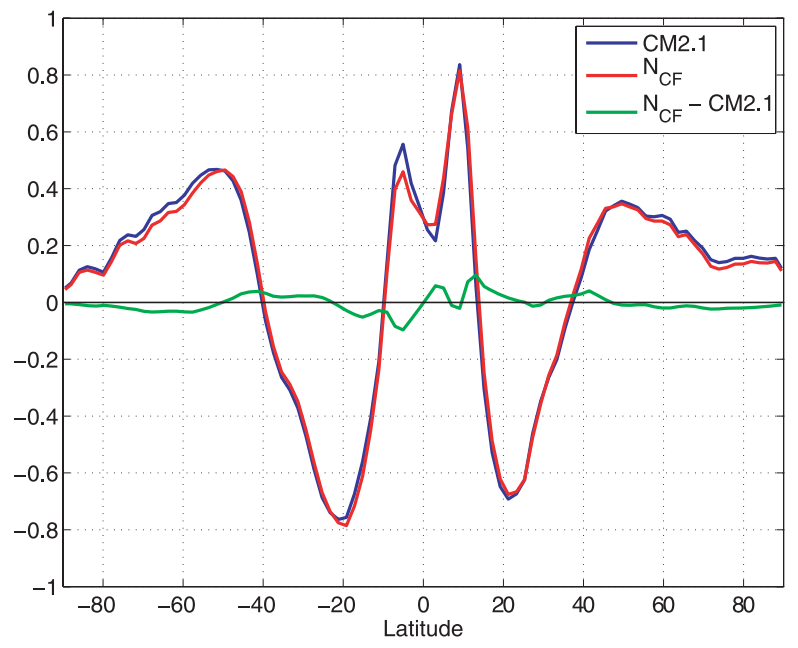

FIG. A2. As in Fig. A1, but for freshwater flux $P-E\left(\mathrm{~m} \mathrm{yr}^{-1}\right)$.

variations. The 3-hourly high-frequency variations in prescribed cloud properties are important to produce a climatological mean CRF close to that in the CM2.1 control run, so that the simulated climatology in $N_{\mathrm{CF}}$ is similar to that in the CM2.1 control run (Figs. A1-A3). If we only prescribe cloud properties with climatological monthly mean values, the resulting climatological mean CRF is very different from that in the CM2.1 control run because the net impact on the mean CRF due to highfrequency variations in cloud properties is missing.

The following is the detailed construction of the prescribed 3-hourly cloud properties values, which are repeated annually. For example, let $\bar{C}_{f}^{c}$ be the climatology monthly mean cloud fraction from the CM2.1 control simulation and $C_{f}$ be the 3-hourly cloud fraction obtained from a 1-yr run of the CM2.1 control, chosen arbitrarily, with monthly mean $\overline{C_{f}}$. The 3-hourly cloud fraction prescribed in $N_{\mathrm{CF}} \widetilde{C_{f}}$ is derived based on $C_{f}$ to maintain high-frequency variations but adjusted to have the same monthly mean as ${\overline{C_{f}}}^{c}$ for every month (i.e., $\widetilde{C_{f}}={\overline{C_{f}}}^{c}$ ) to produce a similar climatology as the CM2.1 control run and to be within the range of $0-1$ through the following equation:

$\widetilde{C_{f}}=\left\{\begin{array}{ll}C_{f}+\frac{{\overline{C_{f}}}^{c}-\overline{C_{f}}}{1-\overline{C_{f}}}\left(1-C_{f}\right) & \text { for }{\overline{C_{f}}}^{c}>\overline{C_{f}} \\ C_{f}+\frac{{\overline{C_{f}}}^{c}-\overline{C_{f}}}{\overline{C_{f}}} C_{f}=C_{f} \frac{\overline{C_{f}}}{\overline{C_{f}}} & \text { for }{\overline{C_{f}}}^{c}<\overline{C_{f}} \\ C_{f} & \text { for }{\overline{C_{f}}}^{c}=\overline{C_{f}}\end{array}\right.$.

The 3-hourly cloud liquid and cloud ice are prescribed in an identical fashion. (a)

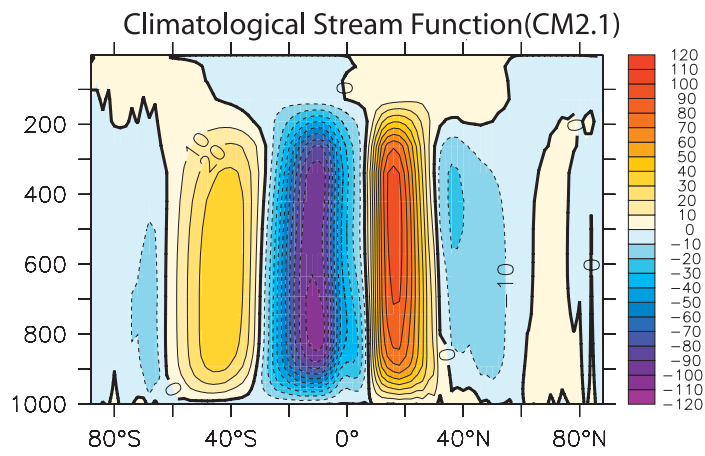

(b) Climatological Stream Function Difference (NCF - CM2.1)

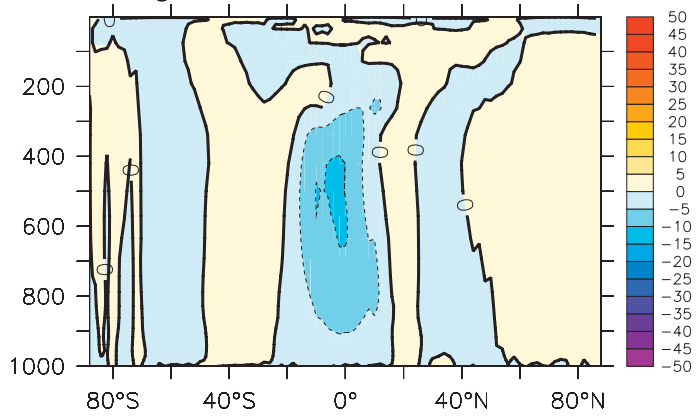

FIG. A3. Zonally integrated climatological annual mean atmosphere streamfunction $\left(10^{9} \mathrm{~kg} \mathrm{~s}^{-1}\right)$ for (a) CM2.1 and (b) the difference between $N_{\mathrm{CF}}$ and CM2.1 climatological means.

The control simulation using $N_{\mathrm{CF}}$ produces a climatology that is similar to that of the CM2.1 control run (Figs. A1-A3) in general. Relative to the CM2.1 control run, the zonally averaged climatological surface temperature from the $N_{\mathrm{CF}}$ control run shows a slight cooling in tropics and a slight warming in the northern polar region (Fig. A1), the zonally averaged climatological freshwater flux $(P-E)$ shows a slight northward shift of the ITCZ (Fig. A2), and the zonal integrated climatological atmospheric streamfunction shows a slight anomalous cross-equatorial Hadley cell with a rising branch north of the equator and a sinking branch south of the equator (Fig. A3).

\section{REFERENCES}

Altabet, M. A., M. J. Higginson, and D. W. Murray, 2002: The effect of millennial-scale changes in Arabian Sea denitrification on atmospheric CO2. Nature, 415, 159-162.

Anderson, J. L., and Coauthors, 2004: The new GFDL global atmosphere and land model AM2 LM2: Evaluation with prescribed SST simulations. J. Climate, 17, 4641-4673.

Cess, R. D., and Coauthors, 1989: Interpretation of cloud-climate feedback as produced by 14 atmospheric general circulation models. Science, 245, 513-516.

Dahl, K. A., A. J. Broccoli, and R. Stouffer, 2005: Assessing the role of North Atlantic freshwater forcing in millennial scale climate variability: A tropical Atlantic perspective. Climate Dyn., 24, 325-346. 
Delworth, T. L., and Coauthors, 2006: GFDL's CM2 global coupled climate models. Part I: Formulation and simulation characteristics. J. Climate, 19, 643-674.

Gupta, A. K., D. M. Anderson, and J. T. Overpeck, 2003: Abrupt changes in the Asian southwest monsoon during the Holocene and their links to the North Atlantic Ocean. Nature, 421, 354-357.

Haug, G. H., K. A. Hughen, D. M. Sigman, L. C. Peterson, and U. Röhl, 2001: Southward migration of the intertropical convergence zone through the Holocene. Science, 293, 1304-1308.

Kang, S. M., I. M. Held, D. M. W. Frierson, and M. Zhao, 2008: The response of the ITCZ to extratropical thermal forcing: Idealized slab-ocean experiments with a GCM. J. Climate, 21, 3521-3532.

Klein, S. A., and D. L. Hartmann, 1993: The seasonal cycle of low stratiform clouds. J. Climate, 6, 1587-1606.

Manabe, S., and R. J. Stouffer, 1995: Simulation of abrupt climate change induced by freshwater input to the North Atlantic Ocean. Nature, 378, 165-167.

McManus, J. F., R. Francois, J. M. Gherardi, L. D. Keigwin, and S. Brown-Leger, 2004: Collapse and rapid resumption of Atlantic meridional circulation linked to deglacial climate changes. Nature, 428, 834-837.

Mikolajewicz, U., T. J. Crowley, A. Schiller, and R. Voss, 1997: Modelling teleconnections between the North Atlantic and North Pacific during the Younger Dryas. Nature, 387, 384-387.

Norris, J., and C. Leovy, 1994: Interannual variability in stratiform cloudiness and sea surface temperature. J. Climate, 7, 1917-1925.

Peterson, L. C., G. H. Haug, K. A. Hughen, and U. Röhl, 2000: Rapid changes in the hydrologic cycle of the tropical Atlantic during the last glacial. Science, 290, 1947-1950.
Soden, B. J., A. J. Broccoli, and R. S. Hemler, 2004: On the use of cloud forcing to estimate cloud feedback. J. Climate, 17, 36613665.

Stott, L., C. Poulsen, S. Lund, and R. Thunell, 2002: Super ENSO and global climate oscillations at millennial time scales. Science, 297, 222-226.

Stouffer, R. J., and Coauthors, 2006: Investigating the causes of the response of the thermohaline circulation to past and future climate changes. J. Climate, 19, 1365-1387.

Vellinga, M., and R. A. Wood, 2002: Global climate impacts of a collapse of the Atlantic thermohaline circulation. Climate Change, 54, 251-267.

Wang, Y. J., H. Cheng, R. L. Edwards, Z. S. An, J. Y. Wu, C.-C. Shen, and J. A. Dorale, 2001: A high-resolution absolute-dated late Pleistocene monsoon record from Hulu Cave, China. Science, 294, 2345-2348.

Weilicki, B. A., B. R. Barkstrom, E. F. Harrison, R. B. Lee, G. Louis Smith, and J. E. Cooper, 1996: Clouds and the Earth's Radiant Energy System (CERES): An earth observing system experiment. Bull. Amer. Meteor. Soc., 77, 853-868.

Wyant, M. C., C. S. Bretherton, J. T. Bacmeister, J. T. Kiehl, I. Held, M. Zhao, S. A. Klein, and B. J. Soden, 2006: A comparison of low-latitude cloud properties and their response to climate change in three AGCMs sorted into regimes using mid-tropospheric vertical velocity. Climate Dyn., 27, 261-279, doi:10.1007/s00382-006-0138-4.

Zhang, R., and T. L. Delworth, 2005: Simulated tropical response to a substantial weakening of the Atlantic thermohaline circulation. J. Climate, 18, 1853-1860. 